\title{
Evaluation of the Apical Sealing Ability of Remaining Gutta-percha after Fiber Post Placement
}

\author{
${ }^{1}$ Wan-Ting Lin, ${ }^{2}$ Salvatore Sauro, ${ }^{3}$ Arlinda Luzi Luzi
}

\begin{abstract}
Aim: The aim of this study is to evaluate the ability of the remaining gutta-percha (GP) in the apical third of root canals after fiber post placement.
\end{abstract}

Materials and methods: Thirty single root canals extracted were sectioned to $18 \mathrm{~mm}$ and divided into three groups. All the root canals were shaped with ProTaper Next (X3 file) and filled with GP and resin-based sealer at three different lengths $(4,5$, and $7 \mathrm{~mm}$ ) from the root apex. The fiber post placement was constructed immediately. The roots were immersed in methylene blue dye for 14 days and transversely sectioned in disks of $1 \mathrm{~mm}$ thick from the apex to the post. The evaluation of the dye penetration was done using a stereomicroscope. One-way analysis of variance (ANOVA) and multiple comparisons of Scheffe's tests were used to test the length of dye penetration. Chi-squared test was used to test dye penetration scale $(p<0.05)$.

Results: In the group 3 where the left (or remaining) GP was 7 $\mathrm{mm}$, the dye penetration scale was lower compared with the other groups $(p<0.05)$. There was less dye penetration at $6 \mathrm{~mm}$ from the apex, and there was no penetration at $7 \mathrm{~mm}$ from the apex. The dye penetration scale was generally decreased from the $1 \mathrm{~mm}$ level disk to the $4 \mathrm{~mm}$ level disk in all the groups.

Conclusion: A $7 \mathrm{~mm}$ length of remnant GP is necessary to obtain an improved apical seal in the cases where a post retention restoration is required in an endodontic treated tooth.

Clinical significance: To maintain the integrity of the apical sealing, it is necessary to leave $7 \mathrm{~mm}$ of GP in the apical third of the root canal. The "standard gold" of $5 \mathrm{~mm}$ of the apical seal with GP cannot prevent apical leakage.

Keywords: Apical sealing ability, Dye penetration, Fiber post, Restoration, Root canal treatment.

How to cite this article: Lin WT, Sauro S, Luzi AL. Evaluation of the Apical Sealing Ability of Remaining Gutta-percha after Fiber Post Placement. World J Dent 2018;9(2):80-86.

Source of support: Nil

Conflict of interest: None

\section{INTRODUCTION}

The root canal is characterized by various anatomic complexities, particularly in the apical third of the root

${ }^{1-3}$ Department of Dentistry, Faculty of Health Science Universidad Cardenal Herrera-CEU, CEU Universities, Alfara del Patriarca, Valencia, Spain

Corresponding author: Arlinda Luzi Luzi, C/Ramon y Cajal s/n, CP. 46115, Alfara del Patriarca, Valencia, Spain, Phone: +0034609712143, e-mail: arlinda.luzi@uchceu.es in which $74 \%$ of accessory canals are found. ${ }^{1}$ Dental professionals have designed new biomaterials and multiple preparation techniques based on their evidence-based knowledge to adapt to different dental anatomies and improve the sealing ability of the root canal. Gutta-percha is the major clinically used root canal filling material, which has advantages, such as biocompatibility, ductility, and malleability. Furthermore, the newly released adaptable GP apparently shows improved adaptation to the apical-third root anatomy, which is created by the rotatory system during the root canal preparation. This rotatory instrumentation has replaced the conventional hand file system, thereby enhancing the shaping ability of the canal and reducing clinical mishaps, such as blockages, ledges, transportations, and perforations. ${ }^{2}$ Eugenol-based sealers have been clinically used for several decades, but many recent studies have proved that eugenol-based sealers significantly reduce the sealing ability and result in apical leakage. ${ }^{3,4}$ Therefore, a resin-based sealer was introduced into the market because of a better sealing strength than the eugenol-based sealer. ${ }^{5}$ Complete sealing of a root canal system is virtually impossible. However, new dental materials and techniques are being introduced to improve apical sealing, thereby, providing an adequate clinical outcome of endodontic treatment. ${ }^{6}$

Endodontically treated teeth have been criticized for weakness of the tooth structure. When endodontic treatment is unavoidable and the remaining dentin is not able to support a restoration, a post is essential to retain the core. The post can be found in the root of a structurally damaged tooth, which requires additional retention and stability. ${ }^{7}$ The post has currently become a main consideration in a largely destroyed coronal tooth, which should be cemented to provide adequate mechanical retention within a root canal and maximal protection from a root fracture. Fiber posts have shown a lower risk for root fracture and an improved retention due to the elastic modulus similar to dentin. ${ }^{8}$ To achieve a good retention of the restoration, it is preferable to use a shorter length fiber post ${ }^{9,10}$ because this reduces the risk of perforation and provides more complete polymerization than the longer post. ${ }^{11}$ Other authors have indicated that there is no difference in the stress distribution among different lengths of fiber posts. ${ }^{12}$ Theoretically, a fiber post combined with a resin luting cement is the most optimal, because it forms a mechanically homogeneous structure 
so that the dentin, post, and cement form a single unit. ${ }^{13}$ Resin luting cement provides both mechanical and biological functions by maintaining an adequate adhesion between the post and dentin, thereby preventing bacterial contamination. However, the adhesion ability and prevention of leakage are determined by the cementation technique. An effective cementation technique can only be achieved if the operator comprehends the limitations of the material and mechanisms involved. ${ }^{14}$

Coronal leakage, which is caused by improper cementation, can result in gap formation between the dentin-cement or cement-post interphase and can result in contact with oral bacterial flora. ${ }^{15}$ Thus, adequate apical sealing is desirable to prevent bacteria from either remaining in root canals after chemical or mechanical preparation or oral bacterial contamination due to coronal leakage, thereby reaching the root apex. ${ }^{15}$ Practically, apical leakage is considered to be the most common cause for endodontic failure. ${ }^{15}$ Hence, the prevention of leakage to achieve complete apical sealing remains unresolved within recent studies. ${ }^{15}$

According to conventional post placement techniques, it is advisable that a minimum of 3 to $5 \mathrm{~mm}$ of GP should remain in the apical portion of the root to achieve a respectable apical seal. ${ }^{16}$ The more apically the post is placed, the higher the retention that will be achieved. ${ }^{17}$ However, the increase in post length does not reduce the cervical stresses to the root walls, as some authors expected; however, increased stresses in the apical regions occur, which promotes the endodontic failure rate. ${ }^{18}$ The situation between increasing post length to maximize the retention while retaining sufficient depth of GP to preserve the apical seal is a challenge for dentists. The null hypothesis chosen in the present study was that different lengths of remaining GP would have no influence on the apical sealing ability after the fiber post is placed. The objective of the present study was to evaluate the apical sealing ability of the remaining GP in the apical third of root canals after fiber post placement.

\section{MATERIALS AND METHODS}

\section{Sample Selection}

In the present study 30 single-rooted extracted human teeth with a straight root canal and fully formed apices and without caries, restoration, or previous endodontic treatment were included. Calcified canals were excluded. Teeth were disinfected using $0.2 \%$ chlorhexidine for 3 days and stored in distilled water until required. All teeth were radiographed mesiodistally and buccolingually to exclude the presence of two canals and two separate apical foramina. In addition, only roots with similar mesiodistal and buccolingual dimensions were selected.

\section{Sample Preparation}

The surfaces of all roots were cleaned using ultrasonic devices. The crowns were sectioned below the cementoenamel junction using a cylindrical diamond bur $(22 \mathrm{~mm}$ $\times 0.2 \mathrm{~mm}$ ) to a length of $18 \mathrm{~mm}$ from the coronal portion to the root apices to facilitate a straight line access. The root canals were randomly allocated into three groups, with each group containing 10 teeth. The samples were stored in distilled water separately at $37^{\circ} \mathrm{C}$ in preparation for the next step.

\section{Root Canal Preparation and Filling}

Root canal preparation and filling were standardized and performed by a single operator to minimize experimental variables. First, we explored the root canal by K-file \#10/0.02 (Dentsply, Switzerland), verified a reproducible glide path, and prepared it to a working length of $0.5 \mathrm{~mm}$ from the apex. The root canals were shaped by ProTaper Next (Dentsply, Switzerland) files mounted on a X-smart handpiece (Dentsply Maillefer, Switzerland) using form X1 (tip 17/4\%) to X3 (30/7.5\%) with the brushing movement and the presence of $5 \%$ sodium hypochlorite $(\mathrm{NaOCl})$ (Royal Dental, Korea) inside the root canal. After shaping the root canals, they were flushed using $5 \mathrm{~mL}$ $\mathrm{NaOCl}, 3 \mathrm{~mL} \mathrm{17 \%}$ trisodium ethylenediaminetetraacetic acid (Royal Dent, Korea), and $5 \mathrm{~mL} \mathrm{NaOCl}$, and then dried with sterile paper points (Henry Schein, UK). Before the canals were filled with GP (ProTaper Next GP system; Dentsply, Switzerland), we used a K-file ${ }^{\#} 0.25$ in a counterclockwise rotation to apply a small amount of endodontic sealer, AH plus ${ }^{\circledR}$ (Dentsply De-trey, Germany), inside the root canals. The endodontic sealer was mixed according to the manufacturer's instructions, and the ProTaper Next GP X3 size was chosen for all the samples coated with a thin layer of sealer before placing inside the root canals. Excess GP was eliminated using Buchanan heat pluggers mounted on System B (Kerr, Italia). The vertical technique using a 0.06 plugger was used to fill the apical part of the root canal doing only the down-pack procedure. The samples were divided into three groups $(n=10)$. In the first group, only $4 \mathrm{~mm}$ of the apical portion was filled, in the second one, $5 \mathrm{~mm}$, and in the third one, $7 \mathrm{~mm}$. In addition, we captured radiographs of all the teeth to ensure that we obtained an acceptable apical seal.

\section{Post Space Preparation and Luting Procedure}

After 48 hours of storage in $37^{\circ} \mathrm{C}$ and $100 \%$ of humidity, the root canals were prepared using a low-speed Peeso reamer (Whaledent, USA) with a contra-angle headpiece, which was provided by the post manufacturers. The final drill used was size 5, red, and $1.25 \mathrm{~mm}$ in diameter. The fiber posts (Medicaline, Italy) of $1.2 \mathrm{~mm}$ diameter were 
used, and they were positioned before we took radiographs to detect any perforation or dislocation. All the root canals were flushed with $2 \mathrm{~mL}$ of alcohol 97\%, after the post space preparation. The fiber posts were cleaned and flushed with alcohol $97 \%$ before cementation. Posts were cemented with a luting cement (Resin Cement $S E^{\circledR}$; Henry Schein, UK), a dual-cure, self-etching adhesive cement. The cementation procedure used was according to manufacturer's instructions, which required a 20 seconds light-curing time. We placed an intraoral tip inside the root canal to apply a small quantity of cement, and the post inserted was covered by a thin layer of luting cement to avoid trapped air. Excess cement was removed before setting and light-curing. The fiber post was cut $2 \mathrm{~mm}$ above the dentin surface using the cylindrical diamond bur ( $22 \mathrm{~mm} \times 0.2 \mathrm{~mm}$ ) (Komet, Germany) after the cementation, and the coronal portion was also sealed using resin cement $\mathrm{SE}^{\circledR}$ (Henry Schein, UK). Radiographs were captured before the teeth were prepared for apical dye penetration. All the specimens were stored at $100 \%$ humidity at $37^{\circ} \mathrm{C}$ for 2 weeks.

\section{Microleakage Test of Apical Dye Penetration}

In all groups, the whole surfaces of the roots except $1 \mathrm{~mm}$ from the apex were homogeneously covered with two layers of transparent nail varnish and left for 1 hour for complete setting. The layer of nail varnish was applied to avoid the penetration of the dye along the root surface, enabling the penetration in the apical portion of the root canal. In addition, the Eppendorf tubes were filled with exactly $200 \mu \mathrm{L}$ of $2 \%$ methylene blue dye solution using a $200 \mu \mathrm{L}$ micropipette with $200 \mu \mathrm{L}$ disposable pipette tips. The specimens were immersed inside the methylene blue dye for 14 days at $37^{\circ} \mathrm{C}$. Teeth were then removed from the dye and rinsed under running water to remove extra dye retained on the external surfaces of roots. The coating of transparent nail varnish was removed using a No. 15 blade. The teeth were separately stored inside the Eppendorf tubes.

\section{Assessment of Results}

The specimens were horizontally sectioned from the apex, and serial disks of $1.0 \mathrm{~mm}$ thick were cut using IsoMet ${ }^{\circledR}$ Low-Speed Saw (Buehler, USA), up until we did not observe any dye penetration in the GP filling in all the specimens. In the first group, 40 disks, in the second group 50 disks, and in the third group 70 disks of $1 \mathrm{~mm}$ thick were obtained. The evaluation of dye penetration length was performed using a stereoscopic microscope at a magnification of $30 \times$ (Leica, Germany). The grade of dye penetration scale was observed using the same stereomicroscope and magnification, and evaluation for leakage was performed using the criteria from 0 to 4: 0 -no dye penetration; $1-$ dye penetration in $1 / 4$ of root canal walls; 2 -dye penetration in $1 / 2$ of root canal walls; 3-dye penetration in 3/4 of root canal walls; and 4 -dye penetration in all the root canal walls.

\section{Statistical Analysis}

Data of dye penetration length were analyzed using one-way ANOVA (SPSS Inc., IBM, USA) and the multiple comparisons of Scheffe's method were conducted to determine significant differences among three groups. Moreover, data for dye penetration scale were assessed within a chi-squared test (SPSS Inc., IBM, USA); $<<0.05$ was considered statistically significant.

\section{RESULTS}

\section{Dye Penetration Length}

The mean dye penetration lengths $(\mathrm{mm})$ and standard deviations (SD) are presented in Table 1. The statistical analyses using one-way ANOVA showed statistically significant differences in dye penetration by methylene blue between the groups III and I ( $p=0.001)$ and between groups III and II ( $p=0.04)$. In addition, there were no statistically significant differences in the comparisons between groups I and II ( $p=0.08)$.

\section{Dye Penetration Scale}

The criteria are demonstrated in Figure 1. We found a statistically significant difference between dye penetration scale and the different levels of specimen disks in group III ( $p=0.038)$, as demonstrated in Table 2 . The dye penetration scale was generally decreased from the 1 $\mathrm{mm}$ level disk to the $4 \mathrm{~mm}$ level disk. In the $1 \mathrm{~mm}$ level disk, $90 \%$ of specimens were of grade IV. However, in the $4 \mathrm{~mm}$ level disk, $50 \%$ of specimens were of grade 0 . There were no statistically significant differences within groups I and II.

\section{Stereomicroscope Observation}

In the observation of different level disks of specimens, we found obvious methylene blue dye infiltration inside the interphases of dentin-cement or cement-post in the $4 \mathrm{~mm}$ remaining GP group. An additional finding was

Table 1: Comparison of dye penetration length $(\mathrm{mm})$ among three groups

\begin{tabular}{lll}
\hline Group & $\begin{array}{l}\text { Mean length of } \\
\text { dye penetration }\end{array}$ & $S D$ \\
\hline I (4 mm of GP) & 3.68 & 0.32 \\
II $(5 \mathrm{~mm}$ of GP) & 4.2 & 0.8 \\
III $(7 \mathrm{~mm}$ of GP) & 5.1 & 0.9 \\
\hline
\end{tabular}



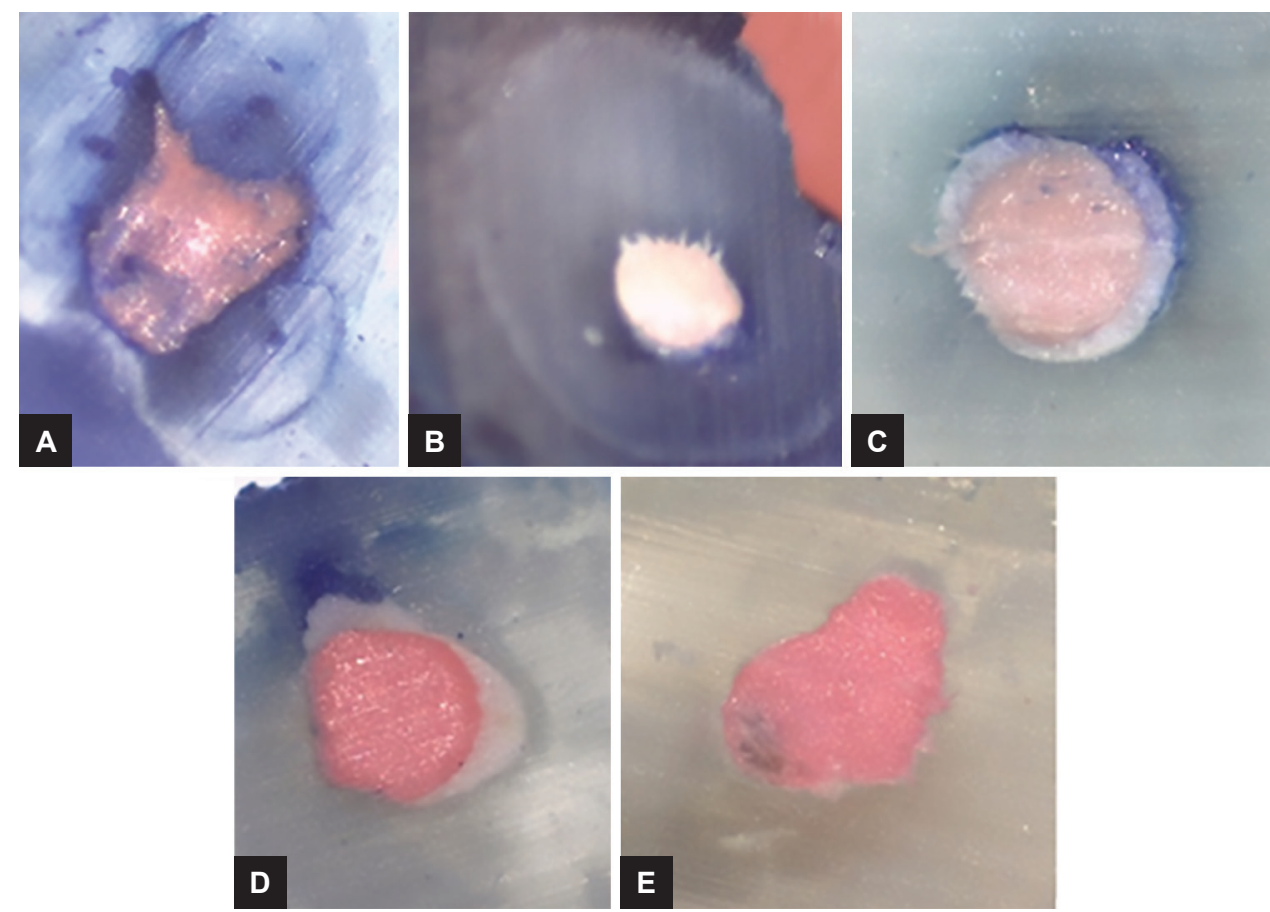

Figs $1 \mathrm{~A}$ to $\mathrm{E}$ : Photographs from a stereomicroscope (magnification $\times 30$ ) to demonstrate examples of different grades of dye penetration scales. (A) grade IV, (B) grade III, (C) grade II, (D) grade I, and $(\mathrm{E})$ grade 0

Table 2: Comparison of dye penetration scales at different level disks within different remaining GP groups

\begin{tabular}{lllllll}
\hline & & & Mean & Chi- & & \\
Group & $n$ & Level of slabs & scale & square & $d f$ & $p$-value \\
\hline I & 10 & $1 \mathrm{~mm}$ from apex & 2.9 & & & \\
& 10 & $2 \mathrm{~mm}$ from apex & 2.5 & 7.827 & 8 & 0.451 \\
& 10 & $3 \mathrm{~mm}$ from apex & 1.7 & & & \\
& 10 & $4 \mathrm{~mm}$ from apex & 1.2 & & & \\
II & 10 & $1 \mathrm{~mm}$ from apex & 2.8 & & & \\
& 10 & $2 \mathrm{~mm}$ from apex & 2.5 & 6.077 & 8 & 0.639 \\
& 10 & $3 \mathrm{~mm}$ from apex & 1.7 & & & \\
& 10 & $4 \mathrm{~mm}$ from apex & 1.3 & & & \\
& 10 & $5 \mathrm{~mm}$ from apex & 0.8 & & & \\
III & 10 & $1 \mathrm{~mm}$ from apex & 3.6 & & & \\
& 10 & $2 \mathrm{~mm}$ from apex & 3.3 & 13.35 & 6 & $0.038^{*}$ \\
& 10 & $3 \mathrm{~mm}$ from apex & 1.5 & & & \\
10 & $4 \mathrm{~mm}$ from apex & 1.2 & & & \\
10 & $5 \mathrm{~mm}$ from apex & 0.9 & & & \\
10 & $6 \mathrm{~mm}$ from apex & 0.5 & & & \\
10 & $7 \mathrm{~mm}$ from apex & 0 & & & \\
\end{tabular}

*Statistical significance was taken as $p<0.05$

that the root canal walls, which had been damaged by the overheated drill, similarly had obvious methylene blue dye infiltrated inside those interphases (Fig. 2).

\section{DISCUSSION}

Any bacterial contamination remaining inside the root canals may infiltrate downward to the apex through the root canals and cause uncontrolled intraradicular infection. ${ }^{19}$ Even with satisfactory root filling, bacterial leakage along the root canal is inevitable over time. ${ }^{20}$ This leakage is clinically undetectable, but is a main factor for endodontic failure. Thus, perfect apical sealing is desirable for preventing bacterial infiltration to the root apex.

Various methods are used for assessing the sealing ability of the root canal. Here, the methylene blue dye penetration methodology was used because it is easy to perform and has a relatively low molecular weight, facilitating easy penetration into accessory canals and dentinal tubules. ${ }^{21}$ Methylene blue is a more sensitive indicator of leakage than other dyes. ${ }^{21}$ The capillarity phenomenon is remarkable in this passive method as the tooth apex is submerged in the dye. ${ }^{5}$ The transversal sectioning method was used to observe the dye penetration surrounding the root canal walls. We did not use longitudinal sectioning, as the section appeared to be a random choice of the cut axis and the liability to cut through the deepest dye penetration point was low, thereby, resulting in an underestimation of leakage and leading to unreliable data. ${ }^{22}$ Here, stereomicroscopic examination was used because of the three-dimensional view of the surface to be examined and because this method does not require pretreatment of specimens.

To achieve a respectable apical seal, the generally accepted best practice is to leave a minimum of $5 \mathrm{~mm}$ of GP in the apical portion of the root. ${ }^{23}$ Some authors suggested that $3 \mathrm{~mm}$ could be the minimum length of GP for a respectable apical seal. ${ }^{24}$ Conversely, Arbamovitz et al ${ }^{23}$ proposed that a reduced length of $3 \mathrm{~mm}$ filling material 

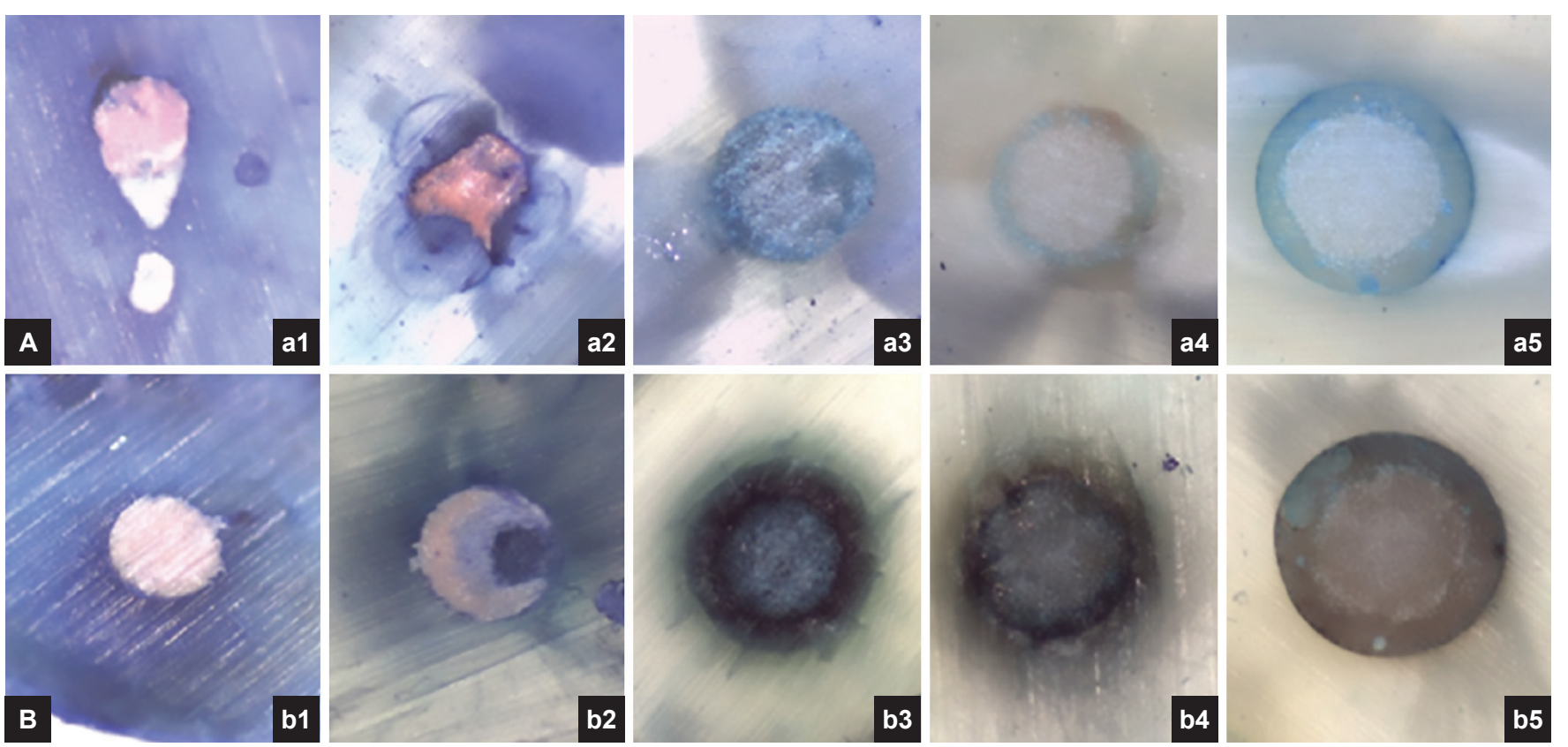

Figs 2A and B: Photographs taken by a stereomicroscope (magnification $\times 30$ ) of different level disks. The infiltration of methylene blue dye in group III (a1) $1 \mathrm{~mm}$ level, (a2) $2 \mathrm{~mm}$ level, (a3) $3 \mathrm{~mm}$ level, (a4) $6 \mathrm{~mm}$ level, and (a5) $7 \mathrm{~mm}$ level. The infiltration of methylene blue dye during overheating drill resulted in damage to the dentin (b1) $1 \mathrm{~mm}$ level slab, (b2) $2 \mathrm{~mm}$ level slab, (b3) $3 \mathrm{~mm}$ level slab, (b4) $4 \mathrm{~mm}$ level slab, and (b5) $5 \mathrm{~mm}$ level slab

produced an unpredictable seal. Hence, this study was designed to compare three different lengths $(4,5$, and $7 \mathrm{~mm}$ ) of remaining GP. Here, the fiber post was placed immediately after post space preparation because, for some authors, there is no difference of leakage between immediate and delayed post cementation after post space preparation. ${ }^{25}$ Padmanabhan et $\mathrm{al}^{26}$ indicate in their study that immediate post space preparation resulted in a relatively lower mean apical dye microleakage.

However, the post space preparation technique has an impact on the root canal surface. Eriksson and Albrektsson ${ }^{27}$ found that $47^{\circ} \mathrm{C}$ is the critical temperature that can damage the bone. That is, an increase of over $10^{\circ} \mathrm{C}$ in temperature while using the reamer or Gates Glidden Drill may cause irreversible damage to the dentin ${ }^{28}$ and may lead to an increased incidence of cracks and fractures. ${ }^{29}$ The structural damage to the dentin may influence the phenomenon of capillarity as observed in Figure 2.

The result of this study could not justify the rejection of the null hypothesis stating that there is no significant difference in the apical sealing ability among three different remaining GP lengths after fiber post placement. Group I had a higher mean and SD of dye penetration length than groups II and III. This finding is similar to that of Mozini et al, ${ }^{30}$ who found that 4 and $6 \mathrm{~mm}$ of remaining GP cannot provide a proper seal because of the high incidence of lateral and accessory canals in the apical region. Regardless of the length of the remaining GP left in the apex, the bacterial leakage persisted. ${ }^{30}$ The findings in this study differ from the results of other authors that showed that a minimum remaining GP of 3 to $5 \mathrm{~mm}$ is sufficient for the apical seal. ${ }^{17,18}$

In groups I and II, we observed that $>50 \%$ of teeth showed dye penetration over the remaining GP, with dye infiltrating in between the interface of dentincement or cement-post interphase, even resulting in the dyeing of the resin cement. This indicated an incomplete polymerization reaction and competition between resin-based sealer and resin cement, resulting in increased solubility of the cement and leakage. ${ }^{17,24}$ Conversely, this result is in agreement with that of previous studies ${ }^{23,24}$ showing that the sealing ability of short root canal fillings is unpredictable, regardless of the root canal filling materials used, with some fillings preserving an adequate apical sealing ability, whereas others losing the apical seal. ${ }^{23}$

The result of the dye penetration scale showed that among the three different groups, grades achieved from highest to lowest were by the 1,2, and $3 \mathrm{~mm}$ level disks. The more apical part of the root canal was found to be influenced by percolation of the tissue fluid. According to Oliver and Abbott, ${ }^{31}$ almost all root canal filling materials assessed failed to produce an apical seal against dye penetration. We only found a statistically significant difference among the seven different level disks in group III. That is, the apical percolation can be stopped through an improved seal using $7 \mathrm{~mm}$ of remnant GP. This finding is partially in agreement with the finding by Mattison et $\mathrm{al}^{17}$ and Hunter et al. ${ }^{18}$ Mattison et $a 1^{17}$ indicates that when the level of GP increased to $7 \mathrm{~mm}$, the degree of 
leakage decreased. In this study, leakage at this level was not found. The same authors indicate that for an adequate apical sealing, at least $5 \mathrm{~mm}$ of GP is necessary. ${ }^{17}$ The results in this study indicate that at least $6 \mathrm{~mm}$ of GP is necessary.

\section{CONCLUSION}

Within the limitations of this study, the following conclusions can be drawn:

- To prevent the apical leakage in the immediate post space, the preparation is necessary to leave more than $6 \mathrm{~mm}$ of GP in the apical portion of the root canal.

- Leaving only $5 \mathrm{~mm}$ of GP to seal the apex cannot guarantee an adequate apical sealing.

- Increasing the depth of the post space preparation in the root canal can lead to an overheating of the dentin surface, raising the apical leakage rate.

- Further clinical studies and long-term observations should be conducted to facilitate a more comprehensive investigation in the apical sealing ability after fiber post placement.

\section{CLINICAL SIGNIFICANCE}

To maintain the integrity of the apical sealing, it is necessary to leave $7 \mathrm{~mm}$ of GP in the apical third of the root canal. The "standard gold" of $5 \mathrm{~mm}$ of the apical seal with GP cannot prevent the apical leakage.

\section{REFERENCES}

1. Vertucci FJ. Root canal anatomy of the human permanent teeth. Oral Surg Oral Med Oral Pathol 1984 Nov;58(5): 589-599.

2. Martinho FC, Freitas LF, Nascimento GG, Fernandes AM, Leite FR, Gomes AP, Camões IC. Endodontic retreatment: clinical comparison of reciprocating systems versus rotary system in disinfecting root canals. Clin Oral Investig 2015 Jul;19(6):1411-1417.

3. Cobankara FK, Adanir N, Belli S, Pashley DH. A quantitative evaluation of apical leakage of four root-canal sealers. Int Endod J 2002 Dec;35(12):979-984.

4. Dias LL, Giovani AR, Silva Sousa YT, Vansan LP, Alfredo E, Sousa-Neto MD, Paulino SM. Effect of eugenol-based endodontic sealer on the adhesion of intraradicular posts cemented after different periods. J Appl Oral Sci 2009 NovDec;17(6):579-583.

5. Mokhtari H, Shahi S, Janani M, Reyhani MF, Zonouzi HR, Rahimi S, Sadr Kheradmand HR. Evaluation of apical leakage in root canals obturated with three different sealers in presence or absence of smear layer. Iran Endod J 2015 Mar;10(2):131-134.

6. Sönmez IS, Sönmez D, Almaz ME. Evaluation of push-out bond strength of a new MTA-based sealer. Eur Arch Paediatr Dent 2013 Jun;14(3):161-166.

7. Bru E, Forner L, Llena C, Almenar A. Fibre post behaviour prediction factors. A review of the literature. J Clin Exp Dent 2013 Jul;5(3):e150-e153.
8. Bergoli CD, de Carvalho RF, Balducci I, Meira JB, de Araújo MA, Valera MC. Influence of fiber post cementation length on coronal microleakage values in vitro and finite element analysis. J Contemp Dent Pract 2014 Jul;15(4):444-450.

9. Santos-Filho PC, Castro CG, Silva GR, Campos RE, Soares CJ. Effects of post system and length on the strain and fracture resistance of root filled bovine teeth. Int Endod J 2008 Jun;41(6):493-501.

10. Scotti R, Valandro LF, Galhano GA, Baldissara P, Bottino MA. Effect of post length on the fatigue resistance of bovine teeth restored with bonded fiber posts: a pilot study. Int J Prosthodont 2006 Sep-Oct;19(5):504-506.

11. dos Santos Alves Morgan LF, Peixoto RT, de Castro Albuquerque R, Santos Correa MF, de Abreu Poletto LT, Pinotti MB. Light transmission through a translucent fiber post. J Endod 2008 Mar;34(3):299-302.

12. Chuang SF, Yaman P, Herrero A, Dennison JB, Chang CH. Influence of post material and length on endodontically treated incisors: an in vitro and finite element study. J Prosthet Dent 2010 Dec;104(6):379-388.

13. Shiratori FK, Valle AL, Pegoraro TA, Carvalho RM, Pereira JR. Influence of technique and manipulation on self-adhesive resin cements used to cement intraradicular posts. J Prosthet Dent 2013 Jul;110(1):56-60.

14. Pegoraro TA, da Silva NR, Carvalho RM. Cements for use in esthetic dentistry. Dent Clin North Am 2007 Apr;51(2): 453-471.

15. Muliyar S, Shameem KA, Thankachan RP, Francis PG, Jayapalan CS, Hafiz KA. Microleakage in endodontics. J Int Oral Health 2014 Nov-Dec;6(6):99-104.

16. Madison S, Zakariasen KL. Linear and volumetric analysis of apical leakage in teeth prepared for posts. J Endod 1984 Sep;10(9):422-427.

17. Mattison GD, Delivanis PD, Thacker RW Jr, Hassell KJ. Effect of post preparation on the apical seal. J Prosthet Dent 1984 Jun;51(6):785-789.

18. Hunter AJ, Feiglin B, Williams JF. Effects of post placement on endodontically treated teeth. J Prosthet Dent 1989 Aug;62(2):166-172.

19. Siqueira JF Jr, Rocas IN. Clinical implications and microbiology of bacterial persistence after treatment procedures. J Endod 2008 Nov;34(11):1291-1301.

20. Karamifar K, Khayat A, Mogharrabi S, Rajaei Y, Saghiri MA. Effect of gravity and capillarity on human saliva penetration in coronally unsealed obturated root canals. Saudi Dent J 2012 Jul;24(3-4):157-162.

21. Ahlberg KM, Assavanop P, Tay WM. A comparison of the apical dye penetration patterns shown by methylene blue and India ink in root-filled teeth. Int Endod J 1995 Jan;28(1):30-34.

22. Camps J, Pashley D. Reliability of the dye penetration studies. J Endod 2003 Sep;29(9):592-594.

23. Abramovitz L, Lev R, Fuss Z, Metzger Z. The unpredictability of seal after post space preparation: a fluid transport study. J Endod 2001 Apr;27(4):292-295.

24. Haddix JE, Mattison GD, Shulman CA, Pink FE. Post preparation techniques and their effect on the apical seal. J Prosthet Dent 1990 Nov;64(5):515-519.

25. Behr M, Rosentritt M, Regnet T, Lang R, Handel G. Marginal adaptation in dentin of a self-adhesive universal resin cement compared with well-tried systems. Dent Mater 2004 Feb;20(2):191-197. 
26. Padmanabhan P, Das J, Kumari RV, Pradeep PR, Kumar A, Agarwal S. Comparative evaluation of apical microleakage in immediate and delayed postspace preparation using four different root canal sealers: an in vitro study. J Conserv Dent 2017 Mar-Apr;20(2):86-90.

27. Eriksson AR, Albrektsson T. Temperature threshold levels for heat-induced bone tissue injury: a vital-microscopic study in the rabbit. J Prosthet Dent 1983 Jul;50(1):101-107.

28. Saunders EM, Saunders WP. The heat generated on the external root surface during post space preparation. Int Endod J 1989 Jul;22(4):169-173.
29. Eriksson JH, Sundström F. Temperature rise during root canal preparation-a possible cause of damage to tooth and periodontal tissue. Swed Dent J 1984;8(5):217-223.

30. Mozini AC, Vansan LP, Sousa Neto MD, Pietro R. Influence of the length of remaining root canal filling and post space preparation on the coronal leakage of Enterococcus faecalis. Braz J Microbiol 2009 Jan;40(1):174-179.

31. Oliver CM, Abbott PV. Correlation between clinical success and apical dye penetration. Int Endod J 2001 Dec;34(8): 637-644. 